\title{
Does eating behaviors among university students in Nigeria differ based on body mass index differences?
}

\author{
Judith Nmor ${ }^{1}$, Kehi Harry Nwaka ${ }^{2}$, Jephtha Christopher Nmor ${ }^{2,3, ~ * ~}$ \\ ${ }^{1}$ Department of Nutrition Sciences, Siebold University, Nagasaki, Japan (formerly) \\ ${ }^{2}$ Department of Animal and Environmental Biology, Delta State University, Abraka, Nigeria \\ ${ }^{3}$ National Mental Support Center for School Crisis, Osaka Kyoiku University, Osaka, Japan
}

\section{Email address:}

jcnmor@yahoo.com (J. C. Nmor)

\section{To cite this article:}

Judith Nmor, Kehi Harry Nwaka, Jephtha Christopher Nmor. Does Eating Behaviors among University Students in Nigeria Differ Based on Body Mass Index Differences? Science Journal of Public Health. Vol. 2, No. 1, 2014, pp. 38-46. doi: 10.11648/j.sjph.20140201.15

\begin{abstract}
Imbalance diet has health implications, thus understanding the correlates of dietary habits are essential. This study seeks to investigate the eating behaviors of university students in relation to body mass index differences with the view to determine the relationship between these habits and BMI status. Anthropometric measurements, eating behaviors and personality traits were determined in a sample of university students from Southern Nigeria. The participants, 108 students $(48.15 \%$ male and $51.85 \%$ female), aged $24.1 \pm 4.1$ filled out a self-reported questionnaire. The present study revealed that the mean factor structure scores in the underweight, normal weight and overweight students appear to be similar but no significant difference was found with respect to weight status. In the overweight category, anxiety showed significant positive associated with sleeping hour per night $(\mathrm{r}=0.36)$ and also a negative correlation with sleeping condition $(r=-0.36)$. Furthermore, emotional eating and personal interest in food was negatively correlated with snacking for all weight categories but the association was strongest for underweight students $(r=-0.81)$, followed by the overweight students $(\mathrm{r}=-0.35)$. Another interesting finding was the strong negative relationship between anxiety and eating of breakfast observed only in the underweight students $(\mathrm{r}=-0.65)$. The results indicate that the same practices can have different effects depending on the BMI of the subject, suggesting that is important to disentangle the subscales of dietary practices. Personality traits showed no significant relationship with BMI, additional research is needed to clearly understand the modulating factors.
\end{abstract}

Keywords: Weight Status, Eating Behaviors, University Students, Body Mass Index Differences, Nigeria

\section{Introduction}

University years can be an exciting time filled with newfound independence and self-discovery; however, there also comes increased responsibility, including making one's own health decisions that may have lasting impacts on health. While this is an important time it can also be difficult for many university students [1]. During this time the development of self-identity, changing support systems, and the shifting of interpersonal influences occur and set this life stage apart from adolescence and adulthood [2]. Nelson et al.[3]opined that the college years have traditionally been considered a time of "optimal health and well-being", however, dietary habits, which may be developed during the college years, can affect the development of chronic disease.

Overweight and obesity is a major public health problem currently, and its prevalence has steadily risen [4]. In the United States, the rates of overweight and obesity have been found to be near $40.0 \%$ in college students; however only $51.0 \%$ believed they were overweight. Thus implying that overweight and obese college student may not be aware of the increased health risk associated with overweight and obesity [5]. Dietary patterns are important precursors of good health and are related to body mass index [6]. Several studies have shown that good eating behavior is essential to live a healthy life and to improve the effectiveness of obesity treatments $[7,8]$.The prevention and management programs for overweight and obesity include the availability of information about eating habits: a potential risk factors for overweight and obesity among various population group particularly university students. 
While availability of information about these health-related factors are important to health educators for designing and implementing health-related education programs that are geared towards maintenance of healthy weight, little is known about the links between BMI status and eating behaviors in Nigerian University students.

In addition to obtaining information on weight distribution, an understanding of the relationship can help health and nutrition educator in planning a better eating therapy for healthy weight maintenance / weight loss program. The main purpose of this study was to clarify whether BMI status would be associated with eating behaviors and their subscales in a sample of university students. It is reasonable to assume that weight status could modulate the associations of eating behaviors. To achieve this aim, the absolute BMI classification was used to classify the students in three categories (underweight, normal weight, and overweight) was adopted.

\section{Methods}

\subsection{Participants and Ethical Consideration}

A total of 202 university students from Delta State University, Abraka voluntarily participated in the study. Of the 202 students, incomplete data were removed and 108 were included in the analysis. Of these, $48.2 \%$ were male while $51.9 \%$ were female. The average age of male participants was $24.7 \pm 4.5$ years while for female was 23.4 \pm 3.6 years. The average age of all participants was $24.1 \pm$ 4.0 years. The participants cut across various faculty and departments. Prior to the study, participants were pre informed of the significance of the research. A written consent was obtained from those who agreed to participate in the study. Ethical approval for the study was granted by the Human Research and Ethics Committee of University of Nagasaki. Permission to conduct the study at the Delta State University was granted by the Dean of student affairs.

\subsection{Anthropometric Assessment and Demographics}

A calibrated scale was used to determine weight. Individuals wore light clothing and no shoes and stood in the middle of the scale, without touching anything, and with their body equally distributed on both feet. Height measurements were taken with a secured graduated ruler. Measurement was taken at the standing height of participants, wearing light clothing and no shoes. Participants stood with their heels together, arms to the side legs straight, and shoulders relaxed, and head in straight position. BMI was then used to assess students' weight status. Weight status was categorized into four: underweight (BMI $\leq 18.5$ ), normal weight (BMI between 18.5 and 24.9), overweight (BMI between 25.0 and 29.9) and obese $(\mathrm{BMI} \geq 30)$. In this study the BMI classification of WHO was used. The sex and age were noted for all study participants.

\subsection{Study Design and Survey Instrument}

The study design was a cross-sectional survey conducted at the Delta State University Abraka campus during the first semester of 2012 Academic session. A self-administered questionnaire on eating habits which was adopted from previous published study $[9,10]$. The questionnaire consisted of different sections assessing the eating behaviors. Demographic data; such as age, sex, living arrangement etc. (1), present condition (2), present eating habits (3) were assessed with questions on frequency of use of fry pan or pot, and kitchen knife, daily meal frequency, meal frequently eaten and cooked. Eating attitudes (4), this section contained 36 items such as "I try to eat a wellbalanced diet," "I like to eat," "I worry about calorie when I eat" etc. (all items are shown in Table 6). The eating attitudes were assessed on a 4 point scale: (1) mostly does not apply, (2) rarely applies, (3) sometimes applies (4) fully applies [10].

Fat-related dietary habits were assessed using the FatRelated Dietary Habits Questionnaire (FDHQ). The use of FDHQ has been widely reported [11-13]. The FDHQ is a behavioral measure of dietary patterns related to selecting and preparing low-fat diets. The scoring system for FDHQ correlates positively with fat intake: higher scores correspond with higher fat intake [13]. Respondents in this study were asked to report their food choices over the past month. The items consisted of 25 items that were then combined into six subscale factors as follows: avoid frying; modify meats to be low in fat; substitute high fat products with low fat; replace meat; avoid fat as flavoring and replace high-fat foods with fruits and vegetables for dessert or snacks. Responses to the items were coded on a 4-point scale (usually or always, often, sometimes, rarely or never), and were scored 1 through 4 to correlate positively with fat intake for respective items on the questionnaire. Five items (fried chicken, fried fish, fried vegetable, fried potato/French fry, and eating vegetables with fat) were reversed-scored so that, a score of one would always reflect lower fat intake. Subscale scores were calculated as the mean of the subscale items. Finally, the University Personality Inventory (UPI), which is a questionnaire developed by the Japan University Health Association to evaluates the mental health of university students [14]. The UPI consists of 60 items and is designed to evaluate six subscales (lie, total, depression, anxiety, obsession and physical complaint). An affirmative response is scored as 1 point.

\subsection{Data Analysis}

The STATISTICA 06J software package (Stat Soft Japan Co., Tokyo, Japan), and graph pad software, were used for data analysis. Where appropriate, Chi-square tests were used to assess the statistical significance. Student $t$-test was used for parametric variables. For variable reduction, factor analyses were conducted for eating attitude using principal factor method with varimax rotation and correlation 
analysis was performed to examine the associations among weight and nutrition knowledge scores, eating attitude factor scores, fat subscale scores and UPI subscale scores. In the correlation analyses, only significant correlations $(P<$ 0.05 ) above 0.2 of the absolute value are shown. All reported $P$ values were made on the basis of two-tailed tests. Differences were considered statistically significant at $P$ value $<0.05$.

\section{Results}

Table1. Characteristics of the participants presented in mean and standard deviation in relation to BMI status ${ }^{a)}$

\begin{tabular}{|c|c|c|c|c|}
\hline Variable & $\begin{array}{c}\text { Underweight } \\
(\mathrm{N}=\mathbf{1 0})\end{array}$ & $\begin{array}{c}\text { Normal weight } \\
(\mathrm{N}=\mathbf{5 7})\end{array}$ & $\begin{array}{c}\text { Overweight } \\
(\mathrm{N}=41)\end{array}$ & $P$ value \\
\hline Age (years) & $21.4 \pm 2.6$ & $23.3 \pm 3.9$ & $25.7 \pm 4.1$ & 0.001 \\
\hline Weight(kg) & $53.1 \pm 4.4$ & $64.6 \pm 9.8$ & $80.5 \pm 11.9$ & 0.001 \\
\hline Height (cm) & $174.6 \pm 8.6$ & $170.1 \pm 10.5$ & $168.3 \pm 12.7$ & 0.283 \\
\hline BMI & $17.4 \pm 0.9$ & $22.3 \pm 1.8$ & $28.3 \pm 2.8$ & 0.001 \\
\hline Hours of sleep/night & $7.5 \pm 1.8$ & $7.8 \pm 1.2$ & $8.2 \pm 1.2$ & 0.245 \\
\hline
\end{tabular}

\subsection{Lifestyle of Participants}

Table 2 presents some of aspects of the lifestyle of the students categorized based on BMI status of the students. Information on the sleeping conditions showed that about $42.1 \%$ of the normal weight students usually sleep well compared to $36.6 \%$ of overweight and $30.0 \%$ of underweight students respectively. There was no significant difference in the sleeping conditions with respect normal and overweight students. Responses to the question on

\subsection{Characteristics of the Participants}

The anthropometric characteristics of the students including hours of sleep per night and grade at the university are presented in Table 1 . There were significant differences in the age. The mean age of the normal weight students was significantly lower compared to the overweight students. The mean BMI increased with increase in mean age.

Table2. Life style of participants presented in number and percent in relation to BMI status ${ }^{a)}$

\begin{tabular}{|c|c|c|c|c|c|}
\hline Questions & Answer level & $\begin{array}{l}\text { Under- } \\
\text { weight } \\
(\mathrm{N}=10)\end{array}$ & $\begin{array}{l}\text { Normal } \\
\text { weight } \\
(\mathrm{N}=57)\end{array}$ & $\begin{array}{l}\text { Over- } \\
\text { weight } \\
(\mathrm{N}=41)\end{array}$ & $P$ value \\
\hline \multirow{5}{*}{ How well do you sleep? } & I hardly ever sleep well & $0(0.0)$ & $3(5.3)$ & $0(0.0)$ & \multirow[t]{5}{*}{0.557} \\
\hline & I usually do not sleep well & $1(10.0)$ & $2(3.5)$ & $1(2.4)$ & \\
\hline & Average & $3(30.0)$ & $16(28.1)$ & $14(34.2)$ & \\
\hline & I usually sleep well & $3(30.0)$ & $24(42.1)$ & $15(36.6)$ & \\
\hline & I always sleep well & $3(30.0)$ & $12(21.1)$ & $11(26.8)$ & \\
\hline \multirow{4}{*}{$\begin{array}{l}\text { How is your present health } \\
\text { condition? }\end{array}$} & $\mathrm{Bad}$ & $0(0.0)$ & $0(0.0)$ & $1(2.4)$ & \multirow[t]{4}{*}{0.577} \\
\hline & Normal & $2(20.0)$ & $12(21.1)$ & $15(36.6)$ & \\
\hline & Good & $3(30.0)$ & $16(28.1)$ & $14(34.2)$ & \\
\hline & Very good & $5(50.0)$ & $29(50.9)$ & $11(26.8)$ & \\
\hline \multirow{5}{*}{$\begin{array}{l}\text { Do you feel stressed } \\
\text { lately? }\end{array}$} & Not at all & $3(30.0)$ & $8(14.0)$ & $6(14.6)$ & \multirow[t]{5}{*}{0.629} \\
\hline & Not really & $3(30.0)$ & $18(31.6)$ & $7(17.1)$ & \\
\hline & Normal & $4(40.0)$ & $27(47.4)$ & $24(58.5)$ & \\
\hline & Rather & $0(0.0)$ & $1(1.8)$ & $2(4.9)$ & \\
\hline & Very & $0(0.0)$ & $3(5.3)$ & $2(4.9)$ & \\
\hline \multirow{3}{*}{$\begin{array}{l}\text { How many cigarettes do } \\
\text { you smoke per day? }\end{array}$} & None & $7(70.0)$ & $53(93.0)$ & $30(73.2)$ & \multirow[t]{3}{*}{0.792} \\
\hline & $1-5$ & $3(30.0)$ & $3(5.3)$ & $6(14.6)$ & \\
\hline & $6-10$ & $0(0.0)$ & $1(1.75)$ & $5(12.2)$ & \\
\hline \multirow{2}{*}{ Are you on a diet? } & Yes & $2(20.0)$ & $17(29.8)$ & $13(31.7)$ & \multirow[t]{2}{*}{0.619} \\
\hline & No & $8(80.0)$ & $40(70.2)$ & $28(68.2)$ & \\
\hline
\end{tabular}

${ }^{a}$ Underweight was only for reference and was not statistically compared

present health condition showed that $26.8 \%$ of the overweight students have a very good health condition. This percentage is lower than that for the normal and underweight students. Though, there was no statistical difference in the health status of the students. Data on the stress status of the students showed that $58.5 \%$ of overweight students reported been under normal stress condition. The smoking rate of the students was higher among overweight students, but there was no significant different between normal and overweight students. 


\subsection{The Frequency of Eating Daily Meals and Snacking in between Meals in Relation to BMI Status}

The percentages of participants who ate breakfast, lunch, and dinner every day and the percentages of those who ate snack in between meal are shown in Table 3. Only 50.0\%, $61.4 \%$ and $78.1 \%$ of the underweight, normal weight and overweight students respectively ate breakfast always. The percentage of students who reported eating dinner always was $90.0 \%, 84.2 \%$ and $87.8 \%$ for underweight, normal weight and overweight students respectively. Lunch was more skipped by overweight students. Snacking in between meals varies among the students. However there was no significant BMI difference with respect to the frequency of eating daily meals and snacking. In terms of the use of kitchen knives, $77.2 \%$ of the normal weight students uses knife almost every day, while $80.0 \%$ of the underweight students uses fry pan or pots almost every day. There was no significant difference between normal and overweight status on the use of kitchen utensils (Table 3).

Table 3. Frequency of consumption of daily meals, snacking in between meals and the use of kitchen utensils in relation to BMI status ${ }^{a)}$

\begin{tabular}{|c|c|c|c|c|c|}
\hline Frequency of eating: & Answer level & $\begin{array}{l}\text { Under- } \\
\text { weight } \\
(\mathrm{N}=10)\end{array}$ & $\begin{array}{c}\text { Normal } \\
\text { weight } \\
(\mathrm{N}=57)\end{array}$ & $\begin{array}{c}\text { Over- } \\
\text { weight } \\
(\mathrm{N}=41)\end{array}$ & $P$ value \\
\hline \multirow{3}{*}{ Breakfast } & Always eat breakfast & $5(50.0)$ & $35(61.4)$ & $32(78.1)$ & 0.715 \\
\hline & Sometimes do not eat breakfast & $4(40.0)$ & $21(36.8)$ & $8(19.5)$ & \\
\hline & Mostly do not eat breakfast & $1(10.0)$ & $1(1.8)$ & $1(2.4)$ & \\
\hline \multirow{4}{*}{ Lunch } & Always eat lunch & $7(70.0)$ & $33(57.9)$ & $22(53.7)$ & 0.703 \\
\hline & Sometimes do not eat lunch & $3(30.0)$ & $23(40.4)$ & $18(43.9)$ & \\
\hline & Mostly do not eat lunch & $0(0.0)$ & $0(0.0)$ & $1(2.4)$ & \\
\hline & Never eat lunch & $0(0.0)$ & $1(1.8)$ & $0(0.0)$ & \\
\hline \multirow{2}{*}{ Dinner } & Always eat dinner & $9(90.0)$ & $48(84.2)$ & $36(87.8)$ & 0.779 \\
\hline & Sometimes do not eat dinner & $1(10.0)$ & $9(15.8)$ & $5(12.2)$ & \\
\hline \multirow{4}{*}{$\begin{array}{l}\text { Snack in between } \\
\text { meals }\end{array}$} & Always eat snacks between meals & $2(20.0)$ & $14(24.6)$ & $10(24.4)$ & 0.694 \\
\hline & Sometimes do not eat snacks between meals & $6(60.0)$ & $36(63.2)$ & $27(65.9)$ & \\
\hline & Mostly do not eat snacks between meals & $2(20.0)$ & $4(7.0)$ & $1(2.4)$ & \\
\hline & Never eat snacks between meals & $0(0.0)$ & $3(5.3)$ & $3(7.3)$ & \\
\hline \multirow{4}{*}{ Use of: Knife } & Almost every day & $6(60.0)$ & $44(77.2)$ & $31(75.6)$ & 0.754 \\
\hline & 3-4 times a week & $2(20.0)$ & $8(14.0)$ & $4(9.8)$ & \\
\hline & 1-2 times a week & $1(10.0)$ & $4(7.0)$ & $5(12.2)$ & \\
\hline & Almost never & $1(10.0)$ & $1(1.8)$ & $1(2.4)$ & \\
\hline \multirow{4}{*}{$\begin{array}{l}\text { Fry pan } \\
\text { or pot }\end{array}$} & Almost every day & $8(80.0)$ & $38(66.7)$ & $27(65.9)$ & 0.701 \\
\hline & 3-4 times a week & $1(10.0)$ & $11(19.3)$ & $5(12.2)$ & \\
\hline & $1-2$ times a week & $1(10.0)$ & $6(10.5)$ & $7(17.1)$ & \\
\hline & Almost never & $0(0.0)$ & $2(3.5)$ & $2(4.9)$ & \\
\hline
\end{tabular}

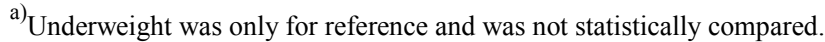

\subsection{Nutrition Knowledge}

The items surveying nutrition knowledge were evaluated and the percentage correctly answered was compared (Data not shown). There was significant differences between normal and overweight status for items 7 (food poisoning is caused by over eating and item number 15 (the amount of calories in $1 \mathrm{~g}$ of alcohol is higher than that of protein). The total correct ratio was slightly highest for normal weight (48.7\%), followed by overweight (45.0\%) and the least for underweight $(44.0 \%)$. There was no significant difference between normal and overweight students.

\subsection{Eating Attitudes}

The 36 items surveying eating attitudes were evaluated and the means were compared between normal and overweight status. The results of these analyses are shown in Table 4. Although, the mean scores showed some variation with BMI, significant differences between normal and overweight status were observed in only item (13). The highest mean scores for underweight students were found on items 1,10 and 15. For normal weight student, item 33, 1 and 21 ranked highest while for the overweight students, items 19, 36 and 1 had the highest mean scores. 
Table4. Item means for eating attitudes in relation to BMI status ${ }^{a)}$

\begin{tabular}{|c|c|c|c|c|c|}
\hline & Items & $\begin{array}{l}\text { Under- } \\
\text { weight } \\
(\mathrm{N}=10)\end{array}$ & $\begin{array}{c}\text { Normal } \\
\text { weight } \\
(\mathrm{N}=57)\end{array}$ & $\begin{array}{c}\text { Over- } \\
\text { weight } \\
(\mathrm{N}=41)\end{array}$ & $P$ value \\
\hline 1 & I try to eat a well-balanced diet. & 3.50 & 3.25 & 3.29 & 0.801 \\
\hline 2 & I seriously would like to learn cooking. & 3.00 & 2.98 & 3.02 & 0.843 \\
\hline 3 & I check for food additives, food coloring, etc. in my food. & 3.00 & 2.44 & 2.78 & 0.104 \\
\hline 4 & I eat precooked food, instant and frozen products, and delivery foods (e.g., pizza). & 2.70 & 2.35 & 2.61 & 0.155 \\
\hline 5 & I take nutritional supplements like vitamin tablets or similar products. & 2.50 & 2.67 & 2.90 & 0.228 \\
\hline 6 & The amount of my food intake varies depending on my mood. & 2.90 & 3.02 & 2.88 & 0.389 \\
\hline 7 & Practicing healthy eating behavior is important to me. & 3.10 & 3.14 & 3.24 & 0.539 \\
\hline 8 & I would like people to commend my cooking. & 2.60 & 3.07 & 3.20 & 0.471 \\
\hline 9 & I buy natural foods and organic vegetables even if they cost more. & 2.40 & 2.84 & 2.83 & 0.941 \\
\hline 10 & I try not to eat too much. & 3.30 & 2.86 & 2.93 & 0.656 \\
\hline 11 & Fast food is delicious and convenient. & 2.60 & 2.72 & 2.80 & 0.592 \\
\hline 12 & I highly value pre-cooked dishes in the supermarket. & 2.60 & 2.32 & 2.46 & 0.450 \\
\hline 13 & I try to eat slowly and chew well. & 3.00 & 2.95 & 3.27 & 0.045 \\
\hline 14 & I like to change the dishes I use depending on my mood. & 2.90 & 2.93 & 2.95 & 0.915 \\
\hline 15 & I feel uneasy about trusting imported foods. & 3.20 & 2.72 & 2.54 & 0.336 \\
\hline 16 & I want to save money on food and spend it on other things & 2.60 & 1.93 & 1.83 & 0.641 \\
\hline 17 & I try to eat a variety of foods. & 3.00 & 3.02 & 3.10 & 0.624 \\
\hline 18 & I try to eat at the same time every day. & 3.00 & 2.47 & 2.46 & 0.956 \\
\hline 19 & I try to enjoy eating my meals. & 3.00 & 3.14 & 3.34 & 0.202 \\
\hline 20 & I think there are many tasty instant noodle soups. & 2.60 & 2.47 & 2.66 & 0.330 \\
\hline 21 & I would like to know more about food nutrients and what functions they have. & 3.10 & 3.23 & 3.15 & 0.600 \\
\hline 22 & I don't care what I eat as long as it fills my stomach. & 2.40 & 1.68 & 2.07 & 0.059 \\
\hline 23 & I want to buy and try out new food products as soon as they are released. & 2.90 & 2.58 & 2.80 & 0.138 \\
\hline 24 & I want to lose weight just by eating a well-balanced diet. & 2.40 & 2.49 & 2.78 & 0.151 \\
\hline 25 & I always drink vitamin drinks. & 2.40 & 2.86 & 3.00 & 0.399 \\
\hline 26 & I don't mind eating the same things every day. & 2.80 & 2.28 & 2.49 & 0.270 \\
\hline 27 & I only want to eat my favorite dishes. & 2.80 & 2.77 & 2.85 & 0.629 \\
\hline 28 & I dislike cooking and cleaning up afterwards. & 2.30 & 2.33 & 2.29 & 0.846 \\
\hline 29 & When food tastes good, I eat more than usual. & 3.20 & 3.11 & 3.07 & 0.855 \\
\hline 30 & I worry about calories when eating. & 3.00 & 2.60 & 2.66 & 0.705 \\
\hline 31 & My eating habits are normal. & 3.10 & 3.18 & 3.29 & 0.458 \\
\hline 32 & It's OK not to eat. & 2.40 & 2.51 & 2.59 & 0.687 \\
\hline 33 & I like to eat. & 3.20 & 3.26 & 3.07 & 0.273 \\
\hline 34 & I feel like eating when I am in a bad mood. & 2.40 & 1.88 & 2.20 & 0.133 \\
\hline 35 & When I see a person eating, I want to eat as well. & 2.90 & 2.33 & 2.66 & 0.148 \\
\hline 36 & I like to strengthen relationships with others by eating together. & 3.20 & 3.18 & 3.32 & 0.442 \\
\hline
\end{tabular}

${ }^{a)}$ Underweight was only for reference and was not statistically compared 
Table 5 presents the mean factor scores for F2 (Emotional and personal eating style) and F3 (Consciousness in food safety)were lower for normal weight students. While the mean score for F1 (Healthy eating habits) was highest among overweight students. There was no significant difference between normal and overweight students.

Table 5. The factor scores of eating attitudes in relation to BMI status ${ }^{a)}$

\begin{tabular}{lcccc}
\hline $\begin{array}{l}\text { Eating attitude } \\
\text { factors }\end{array}$ & $\begin{array}{l}\text { Under- } \\
\text { weight } \\
\mathbf{( N = 1 0 )}\end{array}$ & $\begin{array}{l}\text { Normal } \\
\text { weight } \\
\mathbf{( N = 5 7 )}\end{array}$ & $\begin{array}{c}\text { Over- } \\
\text { weight } \\
\mathbf{( N = 4 1 )}\end{array}$ & $\begin{array}{c}\boldsymbol{P} \\
\text { value }\end{array}$ \\
\hline $\begin{array}{l}\text { F1 (Healthy eating } \\
\text { habits) }\end{array}$ & $27.1 \pm 6.1$ & $27.9 \pm 5.1$ & $28.5 \pm 4.6$ & 0.5148 \\
$\begin{array}{l}\text { F2 (Emotional and } \\
\text { personal eating style) }\end{array}$ & $24.8 \pm 3.7$ & $22.2 \pm 5.6$ & $23.7 \pm 4.4$ & 0.1547 \\
$\begin{array}{l}\text { F3 (Consciousness in } \\
\text { food safety) }\end{array}$ & $15.0 \pm 2.3$ & $14.2 \pm 3.1$ & $14.4 \pm 3.0$ & 0.7352 \\
\hline
\end{tabular}

${ }^{a)}$ Underweight was only for reference and was not statistically compared.

\subsection{Fat-Related Dietary Habits Questionnaire (FDHQ) Subscales Scores}

Table 6 summarizes the mean scores for FDHQ subscales in relation to weight status. Lower scores indicate that fat-lowering behaviors are being practiced more frequently. Normal weight students had the least mean score for modify meat to be low in fat. Replace meats had the least mean score compared to other FDHQ subscales. There were no significant differences with respect to weight status for all subscales.

Table 6. The mean scores for FDHQ subscales in relation to BMI status ${ }^{\text {a) }}$

\begin{tabular}{lcccc}
\hline FDHQ subscales & $\begin{array}{l}\text { Under- } \\
\text { weight } \\
\text { (N=10) }\end{array}$ & $\begin{array}{c}\text { Normal } \\
\text { weight } \\
\mathbf{( N = 5 7 )}\end{array}$ & $\begin{array}{c}\text { Over- } \\
\text { weight } \\
\mathbf{( N = 4 1 )}\end{array}$ & P value \\
\hline $\begin{array}{l}\text { Avoid frying } \\
\text { Modify meat to } \\
\text { be low in fat }\end{array}$ & $9.8 \pm 2.3$ & $9.1 \pm 3.0$ & $9.4 \pm 3.0$ & 0.628 \\
$\begin{array}{l}\text { Substitute high fat } \\
\text { products with low } \\
\text { fat }\end{array}$ & $16.4 \pm 6.6$ & $16.1 \pm 5.6$ & $16.8 \pm 6.0$ & 0.590 \\
$\begin{array}{l}\text { Replace meats } \\
\begin{array}{l}\text { Avoid fat as } \\
\text { flavoring }\end{array}\end{array}$ & $2.6 \pm 0.8$ & $1.9 \pm 1.4$ & $2.4 \pm 1.2$ & 0.128 \\
$\begin{array}{l}\text { Replace high fat } \\
\text { food with fruits } \\
\text { and vegetables }\end{array}$ & $12.6 \pm 3.6$ & $11.9 \pm 3.4$ & $12.5 \pm 3.6$ & 0.401 \\
\hline
\end{tabular}

a) Underweight was only for reference and was not statistically compared.

\subsection{Degree of Mental Health Using the University Personality Inventory (UPI)}

Evaluation of degree of mental health of university students was done using the university personality inventory (UPI). Of the 60 items, only 2 items (4 and 50) showed significant differences between normal weight and overweight status(Data not shown).

\subsection{Subscales of UPI}

Table 7 shows the mean scores for UPI subscales in relation to BMI status. Overweight students had a significant lower score for lie compared to normal weight students, but for other subscales, there were no significant differences between normal and overweight students.

Table 7.The means cores of Subscales of UPIin relation to BMI status ${ }^{a)}$

\begin{tabular}{lcccc}
\hline $\begin{array}{l}\text { Subscales of } \\
\text { UPI }\end{array}$ & $\begin{array}{c}\text { Underweight } \\
(\mathbf{N}=\mathbf{1 0})\end{array}$ & $\begin{array}{c}\text { Normal } \\
\text { weight } \\
(\mathbf{N}=\mathbf{5 7})\end{array}$ & $\begin{array}{c}\text { Overweight } \\
\mathbf{( N = 4 1 )}\end{array}$ & $\boldsymbol{P}$ value \\
\hline Lie & $1.7 \pm 0.8$ & $1.9 \pm 1.1$ & $1.4 \pm 1.0$ & 0.034 \\
Total & $6.3 \pm 3.7$ & $8.1 \pm 5.2$ & $8.1 \pm 5.2$ & 0.949 \\
Depression & $1.6 \pm 1.4$ & $2.1 \pm 2.5$ & $2.0 \pm 2.1$ & 0.895 \\
Anxiety & $1.1 \pm 1.4$ & $1.4 \pm 1.5$ & $1.2 \pm 1.5$ & 0.534 \\
Obsession & $2.0 \pm 1.1$ & $2.2 \pm 1.3$ & $2.4 \pm 1.5$ & 0.491 \\
$\begin{array}{l}\text { Physical } \\
\text { complaint }\end{array}$ & $1.6 \pm 1.2$ & $2.4 \pm 2.0$ & $2.5 \pm 2.3$ & 0.775 \\
\hline
\end{tabular}

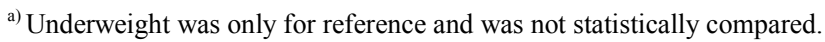

\subsection{Associations between Eating Attitudes, Mental Health, FDHQ Subscales Scores and Eating Behaviors}

The correlation coefficients for the association between eating attitudes factor scores, UPI subscale scores, fatrelated dietary habits and eating behavior by BMI were investigated for underweight, normal weight, and overweight (Data not shown).

The correlation analyses showed variation in the pattern of association of the variables with respect to weight status. Considering underweight, the pattern of association showed that eating attitudes factor scores was significantly correlated with frequency of meal including snacking between meals. UPI subscale scores were associated with life style while FDHQ subscale scores showed significant relationship with health status. Among normal weight students, the pattern of association showed that eating attitudes factor scores relate positively with frequency of meals. UPI subscale scores showed significant relationship with life style and eating attitudes factor scores. For overweight students, eating attitudes factor scores showed significant correlation with life style. Also, UPI subscale scores showed significant relationship with frequency of meals and FDHQ subscales scores correlates significantly with frequency of meal and eating attitudes factor scores.

\section{Discussion}

In recent years several studies on body weight and eating behavior have been published [15-17]. The method f weight recording and assessment varied in the different studies. Recent investigations on weight have used the BMI. However, the results are difficult to compare because some 
authors refer to absolute BMI values $[16,18]$, while others refer to BMI age percentiles [15,19]. The comparability of the studies is made even more difficult by the different samples and study designs. In this study, the distribution of the sample on weight classes was described with reference to absolute BMI. Weight was categorized into underweight, normal and overweight respectively.

The aims of this study were to investigate the eating attitudes and behavior in university students in relation to the weight status (underweight, normal weight and overweight) of the students, and to examine the relationship between BMI and eating attitudes, eating behavior and fatdietary habits and mental health. Data from this study showed that $38.0 \%$ of the studied students were overweight, $52.8 \%$ were normal weight and $9.3 \%$ were underweight. The increasing ratio of weight was quite high. It was also found that about $30.0 \%$ of the student population reported being on a weight loss/control program (dieting) with similar prevalence between normal weight and overweight students.

The present study revealed that the mean eating attitude factors in the underweight, normal weight and overweight students appear to be similar and no significant difference was found with respect to weight status. Also, the FDHQ subscale scores showed no significant difference in the mean scores with respect to the weight status. Except for UPI lie, there was no significant difference in the mean scores of the subscale of the UPI. Given that personality traits or inventory are measurable attributes of people and can be used to explain behavior, correlation analyses were performed to investigate the relationship between eating behavior, eating attitudes scores and personality inventory scores.

The results of the correlation analyses show that the same eating attitude can have opposite effects in subjects whose weight is normal and those who are abnormal. For example, among the underweight students and normal weight students, anxiety showed no significant association with sleeping hours per night and sleeping condition. However, in the overweight category, anxiety showed significant positive associated with sleeping hour per night and also a negative correlation with sleeping condition. This finding agrees with previous reports that have associated anxiety with ranges of sleeping problems [20]. More so, in the overweight students, depression was positively linked with eating breakfast. This could be explained in two ways. First, depressed people are more often than not engaged in eating. Second, higher BMI may result in depression. This observation is in line with studies that have correlated higher BMI with depression $[21,22]$. Furthermore, depressed students are more likely to engage in overeating. This could be associated with mood-eating due to negative emotional state. This implies that overweight students use food as a strategy to help them to face emotional states. This result concurs with previous reports that have identified positive relationship between depression and eating among overweight [23]. Another interesting finding was the strong negative relationship between anxiety and eating of breakfast observed for only the underweight students. This implies that higher frequency of eating breakfast is associated with increased anxiety. Previous study had reported that underweight individuals also reported eating more during positive emotional states and situations but eat less during negative emotional states and situations [24].

This study also found a significant positive association between F2 and stress. This relationship was only observed in underweight and overweight students. These findings indicate that the relationship between F2 and weight may be more linked with underweight and overweight, and eating appears to be a coping strategy for stress among abnormal weight. Furthermore, F2was negatively correlated with snacking for all weight categories but the association was strongest for underweight students, followed by the overweight students. Similar trend was also observed between F3 and snacking. This also is a possible strong indicator of the lesser propensity of snacking among underweight student. In this study, the correlation analyses between the personality traits and eating attitude factors showed some distinctions with respect to weight status as defined by BMI. First, significant high positive correlation was found between F2 and physical complaints in only the underweight students and with obsession in the normal weight students. This implies that emotional and personal eating style may influence mental health. Surprisingly, in the overweight students there was no significant relationship. The reason for this remains unclear and warrants further investigation to clarify the relationship.

Also, results from the correlation analyses found significant associations between eating attitude factors and UPI subscale but not with BMI. Although the reason is largely unknown, previous report also found no significant relationship between emotional eating with BMI [18]. Thus further studies would be required to understand the correlates of eating attitude factors and variability in BMI in university students. The FDHQ subscale showed that higher scores for fat avoidance behavior relates positively with higher score for health status. This was expected as the consumption of excess fat is notorious for leading to weight gain; it can also lead to a number of other, less obvious physical changes that are counterproductive in terms of general health.

This study is limited by the use of a small sample size. This may not unveil the true representation of the eating habits and BMI correlates in the population of students from this region. Further studies are encouraged to build upon this study by using sufficient large sample to explore the underlining factors that may be linked with BMI, eating habits and personality traits. A second possible limitation of this study was that the study design did not assess level of physical activity and food intake frequencies which may have an influence on weight.

Despite the aforementioned limitations, this study adds confidence to the growing pool of literatures on the eating 
habits of university students in the Southern Nigeria. Thus forms an important preliminary step toward establishing the behavioral correlates of weight status as defined by BMI. More so, the correlation analyses of eating attitude factors, UPI and BMI revealed some striking variations with respect to weight status. For example, among the underweight students and normal weight students, anxiety showed no significant association with sleeping hours per night and sleeping condition. However, in the overweight category, anxiety showed significant positive associated with sleeping hour per night and also a negative correlation with sleeping condition. These patterns are interesting findings that requires further clarification.

In conclusion, this study indicates that UPI depression may be modulating BMI in the underweight students and the state of emotional and personal eating style, as well as consciousness in food safety may affect snacking and eating frequencies. The increasing ratio of weight was quite high and requires urgent attention. To reduce the prevalence of overweight, adequate measures are essential to educate the population on the need healthy eating styles.

\section{Acknowledgements}

This study was born out of my M. Sc studies. I am grateful to Dr. M. Tominaga for mentoring me through my graduate studies and for her useful comments. Special thanks to Siebold University, Nagasaki Japan for provision of funding for data collection. Also, we sincerely appreciate the participation of the students.

\section{Conflict of Interest}

The authors declare no conflict of interest.

\section{Authors' Contributions}

$\mathrm{JN}$ is the principal investigator and was responsible for conception of the study, data analysis, interpretation and writing of the thesis. JCN assisted in data entering cleaning, data analysis and interpretation and finalizing the manuscript. KHN was responsible for data collection and coordination of the field work.

\section{References}

[1] Cluskey M, Grobe D. College weight gain and behavior transitions male and female differences. Journal of American Dietetic Association, 2009; 109(2): 325-329.

[2] Arnett JJ. Emerging Adulthood. American Psychologist, 2000; 55(5):469-480.

[3] Nelson MC, Story M, Larson NI, Neumark-Sztainer D, Lytle LA. Emerging adulthood and college-aged youth: an overlooked age for weight-related behavior change. Obesity, 2008; 16(10):2205-2211.

[4] Flegal K. M. , Carroll M. D, Ogden C. L, Johnson C. L.
Prevalence and trends in obesity among US adults, 19992000. Journal of American Medical Association, 2002; 288: 1723-1727.

[5] Boyle JR, LaRose NR. Personal beliefs, the environment and college students' exercise and eating behaviors. American Journalof Health Studies, 2008; 23(4):195-200.

[6] Haveman-Nies A, De Groot LP, VanStaveren WA. Snack patternsof older Europeans. Journal America Dietetic Association, 1998; 98: 1297-1302.

[7] Golay A, Hagon I, Painot D. Personalities and alimentarybehaviors in obese patients. Patient Educationand Counseling, 1997; 31: 103-112.

[8] Stunkard AJ, Messick S. The three-factor eating questionnaireto measure dietary restraint, disinhibition and hunger. Journal of Psychosomatic Research, 2005; 29:71-83.

[9] Tominaga M, Suzuki A, Taguchi M, Takemoto H, Yoon H, Cho K, Ikawa Y. Comparative study of eating habits of university students in Japan and Korea. Journal for the Integrated Study of Dietary Habits, 2009; 20(2):111-120.

[10] Tominaga M, Taguchi M, Suzuki A, Ikawa Y, Youn H, Cho $\mathrm{K}$, Scherling J, Roth R. Differences in self-assessment regarding eating behaviors among female university students living in Japan, Korea, and Austria. Food and Nutrition Sciences, 2012; 3:1673-1681.

[11] Kristal AR, Shattuck AL, Patterson RE. Differences in fatrelated dietary patterns between black, Hispanic, and white women results from the women's health trial feasibility study in minority populations. Public Health Nutrition, 1999; 2(3): 253-262.

[12] Neuhouser ML, Thompson B, Coronado GD, Solomon CC. Higher fat intake and lower fruit and vegetable intakes are associated with greater acculturation among Mexicans living in Washington State, Journal American Dietetic Association, 2004; 104:51-57.

[13] Melnik TA, Spence MM, Hosler AS. Fat-related dietary behaviors of adult Puerto Ricans, with and without diabetes, in New York City. Journal of American Dietetic Association, 2006; 106(9):1419-1425.

[14] Yoshida T, Ichikawa T, Ishikawa T, Hori M. Mental health of visually and hearing impaired students from the viewpoint of the University Personality Inventory. Psychiatry and clinical neurosciences, 1998, 52(4): 413-418.

[15] Sweeney NM, Glaser D, Tedeschi C. The eating and physical activity habits of inner-city adolescents. Journal of Pediatric Health Care, 2007; 21(1):13-21.

[16] Gunes FE, Bekiroglu N, Imeryuz N, Agirbasli M. Relation between Eating Habits and a High Body Mass Index among Freshman Students: A Cross-Sectional Study. Journal of American College and Nutrition, 2012; 31(3):167-74.

[17] Makinen M, Puukko-Viertomies LR, Lindberg N. Body dissatisfaction and body mass in girls and boys transitioning from early to mid-adolescence: additional role of selfesteem and eating habits. BMC Psychiatry, 2012; 12:35.

[18] Goldbacher EM, Grunwald HE, Lagrotte CA, Klotz AA, Oliver TL, Musliner KL, Vanderveur SS, Foster GD. Factor structure of the Emotional Eating Scale in overweight and obese adults seeking treatment. Appetite, 2012; 59(2):610-615. 
[19] Hirschler V, Gonzalez C, Talgham S, Jadzinsky M. Do mothers of overweight Argentinean preschool children perceive them as such?Pediatrics Diabetes, 2006; 7(4):201204.

[20] Vandeputte M, de Weerd A. Sleep disorders and depressive feelings: a global survey with the Beck depression scale. Sleep Medicine, 2003; 4:343-345.

[21] Roberts R. E, Kaplan GA, Shema SJ, Strawbridge W. J: Are the obese at greater risk for depression? American Journal of Epidemiology, 2000; 152:163-170.
[22] Roberts RE, Strawbridge WJ, Deleger S, Kaplan GA. Are the fat morejolly? Annals of behavioral Medicine, 2002; $24: 169-180$.

[23] SantamaríaAR, Vázquez IA, Caballero DP, Rodríguez CF. Eating habits and attitudes and their relationship with Body Mass Index (BMI). European Journal Psychiatric, 2009; 23(4):214-224.

[24] Geliebter A, Aversa A. Emotional eating in overweight, normal weight, and underweight individuals. Eating Behaviors, 2003; 3:341-347. 